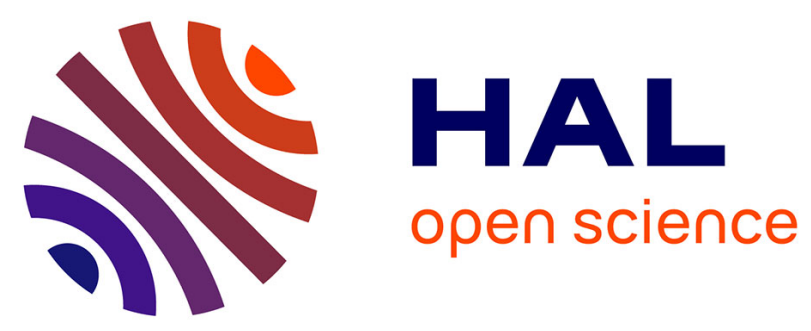

\title{
Evidence for anionic redox activity in a tridimensional-ordered Lirich positive electrode -Li2IrO3
}

Paul E Pearce, Arnaud J Perez, Gwenaelle Rousse, Matthieu Saubanère, Dmitry Batuk, Dominique Foix, Eric Mccalla, Artem M Abakumov, Gustaaf van Tendeloo, Marie-Liesse Doublet, et al.

\section{To cite this version:}

Paul E Pearce, Arnaud J Perez, Gwenaelle Rousse, Matthieu Saubanère, Dmitry Batuk, et al.. Evidence for anionic redox activity in a tridimensional-ordered Lirich positive electrode -Li2IrO3. Nature Materials, 2017, 16 (5), pp.580-586. 10.1038/nmat4864 . hal-03317546

\section{HAL Id: hal-03317546 \\ https://hal.science/hal-03317546}

Submitted on 6 Aug 2021

HAL is a multi-disciplinary open access archive for the deposit and dissemination of scientific research documents, whether they are published or not. The documents may come from teaching and research institutions in France or abroad, or from public or private research centers.
L'archive ouverte pluridisciplinaire HAL, est destinée au dépôt et à la diffusion de documents scientifiques de niveau recherche, publiés ou non, émanant des établissements d'enseignement et de recherche français ou étrangers, des laboratoires publics ou privés. 


\title{
Evidence for anionic redox activity in a tridimensional-ordered Li- rich positive electrode $-\mathrm{Li}_{2} \mathrm{IrO}_{3}$
}

\author{
Paul E. Pearce ${ }^{1,2,3}$, Arnaud J. Perez ${ }^{1,2,3}$, Gwenaelle Rousse ${ }^{1,2,3}$, Mathieu Saubanère, ${ }^{2,4}$ \\ Dmitry Batuk $^{1,5}$, Dominique Foix ${ }^{2,6}$, Eric McCalla ${ }^{1,2,7}$, Artem M. Abakumov ${ }^{8,5}$, Gustaaf Van \\ Tendeloo $^{5}$ Marie-Liesse Doublet ${ }^{2,4}$ and Jean-Marie Tarascon ${ }^{1,2,3, *}$
}

${ }^{1}$ Collège de France, Chimie du Solide et de l'Energie, UMR 8260, 11 place Marcelin Berthelot, 75231 Paris Cedex 05, France.

${ }^{2}$ Réseau sur le Stockage Electrochimique de l'Energie (RS2E), FR CNRS 3459, France.

${ }^{3}$ Sorbonne Universités - UPMC Univ Paris 06, 4 Place Jussieu, F-75005 Paris, France.

${ }^{4}$ Institut Charles Gerhardt, UMR5253, CNRS and Université de Montpellier, Place Eugène Bataillon, F34095 Montpellier

${ }^{5}$ EMAT, University of Antwerp, Groenenborgerlaan 171, B-2020, Antwerp, Belgium. ${ }^{6}$ IPREM/ECP (UMR 5254), University of Pau, 2 av. Pierre Angot, 64053 Pau Cedex 9, France.

${ }^{7}$ CEMS, University of Minnesota, 421 Washington Ave., Minneapolis, MN, USA, 55455.

${ }^{8}$ Skolkovo Institute of Science and Technology, Nobel str. 3, 143026 Moscow, Russia.

* Corresponding author: jean-marie.tarascon@ college-de-france.fr

\begin{abstract}
Lithium-ion battery cathode materials have relied on cationic redox reactions until the recent discovery of anionic redox activity in Li-rich layered compounds which enables capacities as high as $300 \mathrm{mAh} \mathrm{g}^{-1}$. In the quest for new high-capacity electrodes with anionic redox, a still unanswered question was remaining regarding the importance of the structural dimensionality. The present manuscript provides an answer. We herein report on a $\beta-\mathrm{Li}_{2} \mathrm{IrO}_{3}$ phase which, in spite of having the Ir arranged in a tridimensional (3D) framework instead of the typical two-dimensional (2D) layers seen in other Li-rich oxides, can reversibly exchange $2.5 \mathrm{e}^{-}$per Ir, the highest value ever reported for any insertion reaction involving d-metals. We show that such a large activity results from joint reversible cationic $\left(\mathrm{M}^{\mathrm{n}+}\right)$ and anionic $\left(\mathrm{O}_{2}\right)^{\mathrm{n}-}$ redox processes, the latter being visualized via complementary transmission electron microscopy and neutron diffraction experiments, and confirmed by density functional theory calculations. Moreover, $\beta-\mathrm{Li}_{2} \mathrm{IrO}_{3}$ presents a good cycling behaviour while showing neither cationic migration nor shearing of atomic layers as seen in 2D-layered Li-rich materials. Remarkably, the anionic redox process occurs jointly with the oxidation of $\operatorname{~r}^{4+}$ at potentials as low as $3.4 \mathrm{~V}$ versus $\mathrm{Li}^{+} / \mathrm{Li}^{0}$, as equivalently observed in the layered $\alpha-\mathrm{Li}_{2} \mathrm{IrO}_{3}$ polymorph. Theoretical calculations elucidate the electrochemical similarities and differences of the $3 \mathrm{D}$ versus $2 \mathrm{D}$ polymorphs in terms of structural, electronic and mechanical descriptors. Our findings free the structural dimensionality constraint and broaden the possibilities in designing high-energy-density electrodes for the next generation of Li-ion batteries.
\end{abstract}


Renewable energy sources and electric automotive transportation are popular topics in today's energy conscious society, hence placing electrochemical storage as one of the major technological challenges in this new century. Rechargeable Li-ion batteries are the technology of choice for powering electric vehicles and stand as a possible solution for grid applications provided that new advances can be made for improving the performance/cost ratio and lifetime ${ }^{1,2}$. Today's research on positive electrodes is divided into two streams. One deals with polyanionic compounds that favour safety and cost at the expense of energy density ${ }^{3-5}$; and the other with chemical substitutions within the layered oxides which prioritize energy density ${ }^{6}$. The layered oxides are based on $\mathrm{LiCoO}_{2}$, where Co and $\mathrm{Li}$ are each in $2 \mathrm{D}$ hexagonal arrays and $\mathrm{Li}$ intercalates/deintercalates via 2D migration along these sheets. Research in layered oxides has led, with the partial substitution of $\mathrm{Co}$ by $\mathrm{Ni}$ and $\mathrm{Mn}$ in the transition metal layer, to the presently commercialized layered oxide $\mathrm{LiCo}_{1 / 3} \mathrm{Ni}_{1 / 3} \mathrm{Mn}_{1 / 3} \mathrm{O}_{2}$ phase (referred to as Li-NMC) that delivers capacities ranging from 160 to $190 \mathrm{mAh} \mathrm{g}^{-1}$ (ref. 6). Greater capacities ( $>280 \mathrm{mAh} \mathrm{g}^{-1}$ ) were obtained by further substituting the transition metals by $\mathrm{Li}$ so as to produce the $\mathrm{Li}\left[\mathrm{Li}_{\mathrm{x}} \mathrm{Ni}_{\mathrm{y}} \mathrm{Mn}_{\mathrm{z}} \mathrm{Co}_{1-\mathrm{x}-\mathrm{y}-\mathrm{z}}\right] \mathrm{O}_{2}$ layered phases denoted as $\mathrm{Li}$-rich $\mathrm{NMC}^{7,8}$.

The staggering increase in capacity was demonstrated, via complementary electron paramagnetic resonance (EPR) and X-ray photoemission spectroscopy (XPS) measurements performed on ruthenates $\mathrm{Li}_{2} \mathrm{Ru}_{1-y} \mathrm{Sn}_{\mathrm{y}} \mathrm{O}_{3}$ (refs 9,10), to be rooted in the anionic activity with the reversible formation of $\left(\mathrm{O}_{2}\right)^{\text {n- }}$ peroxo-like species accompanied by a massive cationic migration to the depleted $\mathrm{Li}$ layers. An increase in the covalence of the $\mathrm{M}-\mathrm{O}$ bond, via the replacement of a $4 \mathrm{~d}$ metal $\left(\mathrm{Ru}^{4+}\right)$ by a $5 \mathrm{~d}$ metal $\left(\mathrm{Ir}^{4+}\right)$ so as to form $\alpha-\mathrm{Li}_{2} \mathrm{IrO}_{3}$, was shown to prevent this migration ${ }^{11}$. However, $\alpha-$ $\mathrm{Li}_{2} \mathrm{IrO}_{3}$, which enlists a structural transition on charge (from cubic close-packed $\mathrm{O} 3$ to hexagonal close-packed O1), presents lower cycling performances than $\mathrm{Li}_{2} \mathrm{Ru}_{0.75} \mathrm{Sn}_{0.25} \mathrm{O}_{3}$. Whether such a difference is nested in the existence of a structural transition or the simultaneous, rather than successive cationic and anionic redox processes for $\alpha-\mathrm{Li}_{2} \mathrm{IrO}_{3}$ as opposed to $\mathrm{Li}_{2} \mathrm{RuO}_{3}$, remains unanswered. To address these questions, we decided to probe further the effect of modifying the crystal structure on the anionic redox reactivity.

Searching for Li-rich ordered rocksalt structures with enhanced 3D character, we became aware of the $\beta-\mathrm{Li}_{2} \mathrm{IrO}_{3}$ polymorph ${ }^{12,13}$. Its structure exhibits an unusual topology that has recently attracted a lot of interest for magnetism ${ }^{12-16}$. This hyperhoneycomb structure, which consists in a 3D long-range ordered framework of the Ir-O bonds, differs drastically from that of layered honeycomb $\alpha-\mathrm{Li}_{2} \mathrm{IrO}_{3}$ (Supplementary Fig. 1). It is now imperative to determine whether or not the 3D edgesharing connectivity of the $\mathrm{IrO}_{6}$ octahedra in $\beta-\mathrm{Li}_{2} \mathrm{IrO}_{3}$ can accommodate anionic distortions and thereby show the enhanced capacity associated up to now with 2D-layered Li-rich oxides

Pure $\beta-\mathrm{Li}_{2} \mathrm{IrO}_{3}$ powders were prepared by a high-temperature ceramic process from a mixture of $\mathrm{IrO}_{2}$ and $\mathrm{Li}_{2} \mathrm{CO}_{3}$, as described in the Methods. The synchrotron X-ray and neutron powder 
diffraction patterns were fitted using the Rietveld method, confirming the previously reported $F d d d$ hyperhoneycomb structure ${ }^{13}$ (Fig. 1a,b and Supplementary Table 1 and Supplementary Fig. 2). $\beta$ $\mathrm{Li}_{2} \mathrm{IrO}_{3}$ is built on edge-sharing $\mathrm{IrO}_{6}$ octahedra that form a 3D matrix in which $\mathrm{Li}$ ions occupy all available octahedral sites. The structure can therefore accommodate Li migration via corrugated interconnected paths, as shown in Supplementary Fig. 3.

Figure 2a shows the electrochemical performances of $\beta-\mathrm{Li}_{2} \mathrm{IrO}_{3}$ cycled versus $\mathrm{Li}$ in Swagelok cells between 2 and $4.8 \mathrm{~V}$ at a $\mathrm{C} / 10$ rate. Remarkably, all $\mathrm{Li}$ can be removed, leading to an ' $\mathrm{IrO}_{3}$ ' phase which can then uptake nearly $1.8 \mathrm{Li}$ in the following discharge. More specifically, the first charge shows a staircase profile, with the presence of four successive plateaux at 3.45, 3.50, 4.40 and $4.55 \mathrm{~V}$ versus $\mathrm{Li}^{+} / \mathrm{Li}^{0}$, that can be visualized by four peaks in the $\mathrm{dx} / \mathrm{dV}$ plots (Fig. 2b). Such peaks remain well defined on the subsequent discharge. This contrasts with the typical behaviour of Li-rich oxides: a staircase voltage profile on the first charge that converts to an S-shaped profile on the following discharge, which is associated with inter/intra layer cationic migrations ${ }^{9,17}$. It also differs from the electrochemical behaviour of the $\alpha-\mathrm{Li}_{2} \mathrm{IrO}_{3}$ polymorph, which shows only two oxidation plateaux that progressively transform upon cycling into S-shaped profiles ${ }^{11}$. Fig. $2 b$ also shows a minor downshift in voltage of the anodic and cathodic peaks with continued cycling up to $4.8 \mathrm{~V}$, which can be avoided by limiting the cutoff voltage to 4.5 V (see Supplementary Fig. 4).

To better understand $\mathrm{Li}$-driven structural changes in $\beta$ - $\mathrm{Li}_{2} \mathrm{IrO}_{3}$, in situ $\mathrm{X}$-ray powder diffraction (XRD) was performed (Fig. 2c). We observe four successive biphasic regions, each of them corresponding to a well-defined plateau in the voltage-composition curve (Fig. 2c). Each inflexion point, at $x=1.5, x=1, x=0.35$ and $x=0$ in $\beta-\mathrm{Li}_{x} \mathrm{IrO}_{3}$, corresponds to a single phase. The TEM analysis of these single phases reveals that the arrangement of the Ir atoms is preserved even when all $\mathrm{Li}$ is extracted (Supplementary Fig. 5). Refined XRD patterns (shown in Supplementary Fig. 6) demonstrate that when charging from $\mathrm{x}=2$ to $\mathrm{x}=1$, the $F d d d$ space group is preserved with only a change in the lattice parameters (Fig. 2c,d). When $x$ reaches 0.35 , the symmetry of the material is lowered to the monoclinic, $C 2 / c$ space group (note the corresponding reflection splitting in the $18.5^{\circ}-19.5^{\circ} 2 \theta$ region in Fig. $2 d$ and in Supplementary Fig. $6 c$ and Supplementary Table 2$)$. The fully oxidized phase $\mathrm{Li}_{\mathrm{x}} \mathrm{IrO}_{3}(4.8 \mathrm{~V}, \mathrm{x} \sim 0)$ shows a significant broadening of the peaks, most likely associated with increasing strain in the structure, and can also be indexed in the $C 2 / c$ space group with a smaller $\beta$ angle as compared to $\mathrm{Li}_{0.35} \mathrm{IrO}_{3}$ (Supplementary Fig. 6d). The feasibility of removing all $\mathrm{Li}^{+}$ions from $\beta-\mathrm{Li}_{2} \mathrm{IrO}_{3}$, while preserving the structural framework, is somewhat spectacular as this is normally seen only in polyanionic and spinel compounds; with the main difference that two atoms out of six (that is, 33\%) can be extracted from $\beta-\mathrm{Li}_{2} \mathrm{IrO}_{3}$, whereas it is only one out of seven (that is, $15 \%$ ) for $\mathrm{LiFePO}_{4}$ or $\mathrm{LiMn}_{2} \mathrm{O}_{4}$. Upon discharge, the XRD pattern of the fully charged sample converts back to that of the pristine phase via the same sequence of structure transformations. This demonstrates the 
reversibility of the charge/discharge process but does not provide clues on the nature of the involved redox species.

To grasp further insights into the mechanisms of the Li-redox processes in $\beta$ - $\mathrm{Li}_{\mathrm{x}} \mathrm{IrO}_{3}$, XPS measurements were carried out on the pristine sample $(\mathrm{x}=2)$, on ex situ oxidized samples at $\mathrm{x}=1.5,1$, $0.35,0$, and on the compound that was charged to $4.8 \mathrm{~V}$ and discharged to $2 \mathrm{~V}$ versus $\mathrm{Li}^{+} / \mathrm{Li}^{0}$. Figure 3a,b shows a shift of the Ir $4 \mathrm{f}$ peak towards lower energies together with the appearance of an extra $\mathrm{O}$ 1s peak (red peak in Fig. 3a) associated with the formation of peroxo-like $\left(\mathrm{O}_{2}\right)^{\text {n- }}$ species during the charging process. During the subsequent discharge, the opposite variations are seen, indicating a reversible oxidation/reduction of both metal and oxygen upon cycling, as reported for the previously investigated Ru- and Ir-based layered Li-rich compounds9-11. Moreover, Fig. 3d shows that the portion of redox that can be attributed to peroxo-like species increases monotonously until the end of charge at $4.8 \mathrm{~V}(\mathrm{x}=0)$, where it reaches $\sim 55 \%$. Similarly, the evolution of the Ir $5 \mathrm{~d}$ population based on the Ir valence bands (Fig. 3c) indicates that the metal oxidation takes place preferentially during the first part of charge. Overall, these results indicate that Li-deinsertion-driven cationic and anionic oxidation processes in $\beta-\mathrm{Li}_{2} \mathrm{IrO}_{3}$ occur conjointly, as seen in $\alpha-\mathrm{Li}_{2} \mathrm{IrO}_{3}$ (ref. 11).

At this stage, to explore the synergy between redox processes and structural transformations, we exploit complementary neutron powder diffraction, high-resolution scanning transmission electron microscopy (STEM) and density functional theory (DFT) calculations. An ex situ neutron powder diffraction (NPD) pattern was recorded on the sample charged to $4 \mathrm{~V}\left(\mathrm{Li}_{\mathrm{x}} \mathrm{IrO}_{3}\right.$ with $\left.\mathrm{x}=1\right)$. The NPD pattern can be indexed with the $\underline{F d d d}$ orthorhombic space group (Fig. 1d), with lattice parameters reported in Table 1. Moreover, Rietveld refinements indicate that the remaining Li occupies a new tetrahedral position (Fig. 1d,e), denoted Li3 in Table 1. The structure refinement also reveals significant changes in the geometry of the $\mathrm{IrO}_{6}$ octahedra (Fig. 1c and f). First, the average $\mathrm{Ir}-\mathrm{O}$ distance reduces from $2.028 \AA$ in the pristine structure to $1.972 \AA$ in the charged sample, concomitantly with the decrease of the ionic radius of the Ir cations from $0.625 \AA$ ( $\left.\mathrm{Ir}^{4+}\right)$ to $0.57 \AA\left(\mathrm{Ir}^{5+}\right)$ 18. Moreover, the shortest $\mathrm{O}-\mathrm{O}$ bond in the $\mathrm{IrO}_{6}$ octahedra is significantly shorter in the charged material (2.53 $\AA$, Fig. 1f) than in the pristine material (2.75 $\AA$, Fig. 1c), which is indicative of the formation of peroxo-like species on charge.

To track the deformation of the $\mathrm{IrO}_{6}$ octahedra, we used [110] annular bright-field STEM (ABF-STEM) images of the pristine and mid-charged, $x=1$, samples (Fig. 4), where cationic and anionic species form individual atomic columns (Supplementary Figs 7 and 8). In the image of the pristine material, the $\mathrm{O} 1$ and $\mathrm{O} 2$ atomic columns are well resolved; the image also contains a weak signal from the Li columns in the octahedral positions (see the intensity profiles). In the charged $\mathrm{x}=1$ material, the signal from $\mathrm{Li}$ in the octahedral sites is drastically reduced in line with the NPD results. The $\mathrm{O} 1$ positions remain clearly visible while the $\mathrm{O} 2$ positions become closely projected to the Ir columns. The shortening of the $\mathrm{Ir}-\mathrm{O} 2$ projected distances due to the shortening of $\mathrm{O} 2-\mathrm{O} 2$ distances 
can be seen in the [110] projection as 'flattening' of the $\mathrm{IrO}_{6}$ octahedra. Together, the experimental STEM images and the NPD data unambiguously prove the formation of peroxolike species in the $\mathrm{x}=$ 1 sample, in good agreement with XPS measurements. The ABF-STEM analysis of more oxidized materials is hindered by the increasing beam sensitivity of the structures (for $x=0.35$ image, see Supplementary Fig. 9). Nevertheless, DFT calculations reveal that the removal of one more lithium from $\mathrm{LiIrO}_{3}$ leads to a monoclinic distortion of the structure which is in perfect agreement with the experimental data (see Supplementary Table 3) and can be explained by a significant shortening of the O1-O1 distances to reach equivalent $\mathrm{O} 1-\mathrm{O} 1$ and $\mathrm{O} 2-\mathrm{O} 2$ distances around $2.4 \AA$ in the fully delithiated $\mathrm{IrO}_{3}$ phase (see Supplementary Table 4).

Turning back to the cycling performances of $\mathrm{Li} / \beta-\mathrm{Li}_{2} \mathrm{IrO}_{3}$ cells (Fig. 5a), we observed $15 \%$ capacity decay over the first 30 cycles when the cells are cycled between $2 \mathrm{~V}$ and $4.8 \mathrm{~V}$ versus $\mathrm{Li}^{+}$ $/ \mathrm{Li}^{0}$, together with a $98.5 \%$ coulombic efficiency and an excellent rate capability since $80 \%$ of the initial capacity is accessible at a $4 \mathrm{C}$ discharge rate (Supplementary Fig. 10). To understand the origin of the capacity decay, $\mathrm{Li} / \beta-\mathrm{Li}_{2} \mathrm{IrO}_{3}$ cells were cycled over different potential windows. There is only a minor decay when the cycling voltage is maintained below $4.45 \mathrm{~V}$. In contrast, capacity loss is observed when the cells are cycled in the $4.45 \mathrm{~V}-4.8 \mathrm{~V}$ voltage domain. Electrolyte decomposition, which is enhanced at high voltage, and the poor reversibility of the structural transformation that yields ' $\mathrm{IrO}_{3}$ ' above $4.45 \mathrm{~V}$, are most likely at the origin of this decay, but we cannot at present determine which one predominates.

Finally, for sake of completion, we checked the possibility of reducing further the material and, surprisingly, $\beta-\mathrm{Li}_{2} \mathrm{IrO}_{3}$ can reversibly uptake in a sustained way (Fig. $5 \mathrm{~b}$ ) $0.5 \mathrm{Li}$ per formula unit at a potential of $\sim 1.45 \mathrm{~V}$ versus $\mathrm{Li}^{+} / \mathrm{Li}^{0}$ via two biphasic processes (Supplementary Figs 11 and 12). Overall, the $\beta$ polymorph can therefore reversibly exchange $2.5 \mathrm{Li}$. This is, to our knowledge, the first compound ever reported that cycles more than $2 \mathrm{e}^{-}$per transition metal via reversible (de)intercalation reactions.

The feasibility of preparing Li-free ' $\mathrm{IrO}_{3}$ ' electrochemically (confirmed by atomic absorption spectroscopy) fully validates our anionic redox concept. Bearing in mind the presence of $\mathrm{Ir}^{5+}$ and $\left(\mathrm{O}_{2}\right)^{\mathrm{n}-}$ species in this compound, we can estimate the value of $\mathrm{n}$ to be 3.3. Thus ' $\mathrm{IrO}_{3}$ ' can be written as ' $\mathrm{Ir}^{5+}\left(\mathrm{O}_{3}\right)^{5-}$, to maintain charge neutrality. Such a final stage could be obtained neither with layered $\alpha-$ $\mathrm{Li}_{2} \mathrm{IrO}_{3}$ nor with layered Li-rich NMC materials, mostly because they both lack the rigidity provided by the $3 \mathrm{D}$ hyperhoneycomb network. Similarly, this polymorph differs from $\mathrm{Li}_{1.3} \mathrm{Nb}_{0.3} \mathrm{M}_{0.4} \mathrm{O}_{2}(\mathrm{M}=$ $\mathrm{Mn}, \mathrm{Fe})$ and $\mathrm{Li}_{1.3} \mathrm{Nb}_{0.43} \mathrm{M}_{0.27} \mathrm{O}_{2}(\mathrm{M}=\mathrm{Co}, \mathrm{Ni})^{19}$, which are described as cation-disordered rocksalt phases and for which the $\mathrm{Li}, \mathrm{Nb}$ and $\mathrm{M}$ disorder precludes a long-range ordered 3D network of the metal-oxygen bonds. Moreover, because of sluggish kinetics, temperatures of $60{ }^{\circ} \mathrm{C}$ are necessary to remove one out of the $1.3 \mathrm{Li}^{+}$in these phases, while all $\mathrm{Li}$ can be removed from $\beta-\mathrm{Li}_{2} \mathrm{IrO}_{3}$ at room temperature. Lastly, within this context of high-capacity materials, it is worth mentioning the recently 
reported rocksalttype nanostructured ' $\mathrm{Li}_{4} \mathrm{Mn}_{2} \mathrm{O}_{5}$ ' phase20, whose composition and structure are not yet determined.

We have previously shown, via the study of $\alpha-\mathrm{Li}_{2} \mathrm{IrO}_{3}{ }^{11}$, that it is possible to suppress the typical electrochemical behaviour of Li-rich layered oxides, where a staircase voltage profile on charge is followed by an S-type profile on discharge, by increasing the covalence of the $\mathrm{M}-\mathrm{O}$ bond via the use of heavier $5 \mathrm{~d}$ metals. This finding is reinforced with the $\beta-\mathrm{Li}_{2} \mathrm{IrO}_{3}$ polymorph which, in contrast to the $\alpha$ polymorph, does not show the resurgence of the S-shape after several cycles, and remains stable after full $\mathrm{Li}$ removal. The elastic constants of both the $\alpha$ - and $\beta-\mathrm{Li}_{x} \mathrm{IrO}_{3}$ polymorphs were computed from DFT as a function of the Li content x (Supplementary Fig. 13). The results show that the $\beta$-phase displays a more isotropic mechanical response to stress than the $\alpha$-phase, as expected from its 3D structure. Moreover, the $\alpha-\mathrm{Li}_{\mathrm{x}} \mathrm{IrO}_{3}$ phase at low $\mathrm{Li}$ content is predicted to be thermodynamically unstable with respect to shear stress, while the $\beta$-phase remains mechanically stable down to $\mathrm{x}=0$.

The oxidation path for $\beta-\mathrm{Li}_{2} \mathrm{IrO}_{3}$ counts several steps that we could ascribe to structural phase transformations. The electronic structures computed for $\beta$ - $\mathrm{Li}_{\mathrm{x}} \mathrm{IrO}_{3}$ at different $\mathrm{Li}$ content $(\mathrm{x}=2,1,0)$ confirm the synergetic cationic and anionic redox processes at each step of the delithiation, with an equivalent contribution of $\mathrm{Ir}$ and $\mathrm{O}$ in the band lying below the Fermi level for $\mathrm{Li}_{2} \mathrm{IrO}_{3}$ and $\mathrm{LiIrO}_{3}$ (Fig. 6a, left). Focusing on the oxygen network (from now on, $\mathrm{O} 1$ and $\mathrm{O} 2$ refer to the Fddd description), the progressive formation of peroxo-like species is clearly visible through the discretization of the $\mathrm{O}\left(2 \mathrm{p}\right.$ )-band when going from $\mathrm{Li}_{2} \mathrm{IrO}_{3}$ to $\mathrm{IrO}_{3}$ (see the $\mathrm{O}(2 \mathrm{p}$ )-band in Fig. 6a, right). The evolution of the band lying just above the Fermi level shows that $\mathrm{O} 2$ is mostly involved in the oxidation process from $\mathrm{Li}_{2} \mathrm{IrO}_{3}$ to $\mathrm{LiIrO}_{3}$, while $\mathrm{O} 1$ is mostly involved in the oxidation process from $\mathrm{LiIrO}_{3}$ to $\mathrm{IrO}_{3}$. Moreover by monitoring the oxidation degree of $\mathrm{O} 1$ and $\mathrm{O} 2$ via the variation of O1-O1 and O2-O2 distances for each voltage-composition plateau (Supplementary Table 4) we could confirm, as depicted by histograms in Fig. 6b, that both oxygens are equivalently oxidized during the first $(3.45 \mathrm{~V})$ and the fourth processes $(4.55 \mathrm{~V})$ while $\mathrm{O} 2$ and $\mathrm{O} 1$ are mostly involved in the second $(3.50 \mathrm{~V})$ and third $(4.40 \mathrm{~V})$ oxidation processes, respectively. Such minor local structural changes could be at the origin of the small potential splitting in the low- and high-voltage plateaux.

In contrast, the one volt step increase at $\mathrm{x}=1$ could be due to the redistribution of the $\mathrm{Li}^{+}$ions from the octahedral to the tetrahedral site, as observed by neutron diffraction, since a step of similar amplitude was for instance observed in spinel $\mathrm{Li}_{2} \mathrm{Mn}_{2} \mathrm{O}_{4}$ upon the de-insertion of one $\mathrm{Li}$ when the remaining $\mathrm{Li}^{+}$ions move from octahedral to tetrahedral sites. To further support this hypothesis, the electronic band structure was calculated for the $\beta-\mathrm{Li}_{2} \mathrm{IrO}_{3}$ and for the $\alpha-\mathrm{Li}_{2} \mathrm{IrO}_{3}$ polymorph for sake of comparison (Supplementary Fig. 14 and Supplementary Table 5). They are nearly identical despite different crystal structures, suggesting that the topology of $\mathrm{IrO}_{6}-\mathrm{IrO}_{6}$ interactions is similar in both systems, and that equivalent electrochemical responses should be expected. This is clearly the case for the low-voltage processes, for which both phases undergo a joint cationic/anionic redox at very close 
average voltages $(\sim 3.45 \mathrm{~V})$. On the other hand, for the high-voltage process, the two polymorphs show different voltages $\left(\sim 4.45 \mathrm{~V}\right.$ for $\beta$ and $\sim 4.2 \mathrm{~V}$ for $\left.\alpha^{11}\right)$, suggesting also the importance of the differing structural changes, namely the modification of Li sites from octahedral to tetrahedral in the $\beta$-phase and the phase transition involving a gliding of $\mathrm{IrO}_{6}$ layers in the $\alpha-\mathrm{Li}_{2} \mathrm{IrO}_{3}$ polymorph.

The band structures of both polymorphs are consistent with the formation of peroxo-like species at the early stage of the oxidation process. Thus, it is tempting to see the existence of a distorted $\mathrm{IrO}_{6}$ octahedron in the pristine material as an indicator for anionic redox activity at low potential, therefore opening new directions for novel high-energy-density materials. This is certainly the case for both $\beta$ - and $\alpha-\mathrm{Li}_{2} \mathrm{IrO}_{3}$, but further examples are needed to ensure the robustness of such a correlation. This structural feature in the pristine material could imply the presence of ligand holes in the pristine compound, not spotted by XPS, which would be neutralized by the addition of extra electrons, via classical electrochemical reduction, provided that the structure has extra sites to accommodate $\mathrm{Li}^{+}$ions. Along that line, the possibility to further reduce $\beta-\mathrm{Li}_{2} \mathrm{IrO}_{3}$ is not surprising, and fully complies with the ligand hole chemistry pioneered by $\mathrm{J}$. Rouxel for chalcogenides ${ }^{21-23}$.

In this report, we have demonstrated the feasibility of triggering anionic redox activity in ordered 3D compounds. Moreover, we show that a 3D structure can present some advantages such as the feasibility to remove all $\mathrm{Li}$, owing to a greater stability of the structure and to achieve better capacity retention than its layered counterpart thanks to the absence of shear stresses associated with the gliding of the planes during cycling. Several interesting findings are worth mentioning. Firstly, there is a concomitant occurrence of cationic and anionic redox processes while such processes are decoupled in $\mathrm{Li}_{2} \mathrm{RuO}_{3}$ (ref. 9), with the anionic redox activity being triggered at potentials as low as $3.4 \mathrm{~V}$ versus $\mathrm{Li}^{+} / \mathrm{Li}^{0}$. Secondly, the anionic redox mechanism progresses continuously on charge, irrespective of the structural transitions observed, suggesting that the voltage needed for anionic redox phenomena is closely linked to the M-O bonding and can therefore be tuned. Thirdly, we show that these redox processes do not trigger transition metal migrations as in the Ru-based layered compounds ${ }^{10}$. Lastly, the $3 \mathrm{D} \beta-\mathrm{Li}_{2} \mathrm{IrO}_{3}$ compound can be both fully oxidized and reduced, a feature not present with Li-rich NMC layered oxides. These findings offer additional clues to theorists to further investigate the physics at work in these Li-rich oxides.

Overall, with the reversible uptake of $2.5 \mathrm{Li}$ per transition metal, the $\beta-\mathrm{Li}_{2} \mathrm{IrO}_{3}$ polymorph nearly sets a record. Another unique feature of $\beta-\mathrm{Li}_{2} \mathrm{IrO}_{3}$ is its ability to lose all of its $\mathrm{Li}$ atoms, that represents $33 \%$ of the atoms in the formula unit while keeping its structural integrity. This situation has never been seen in any layered oxides. Consequently, by increasing the structural dimensionality in oxides, we now have access to a rich crystal chemistry, thereby opening wide the research field for new high-capacity electrodes relying on reversible anionic redox activity. 


\section{METHODS:}

\section{Synthesis}

$\beta-\mathrm{Li}_{2} \mathrm{IrO}_{3}$ was prepared from $\mathrm{IrO}_{2}$ (Sigma Aldrich, 99.9\%) and $\mathrm{Li}_{2} \mathrm{CO}_{3}$ (Sigma Aldrich, 99.0\%) with $20 \%$ excess. The reactants where mixed by ball-milling $30 \mathrm{~min}$, pelletized and fired at $1000^{\circ} \mathrm{C}$ for 86 hours under $\mathrm{O}_{2}$ atmosphere.

\section{Electrochemical characterization}

$\beta-\mathrm{Li}_{2} \mathrm{IrO}_{3}$ was cycled versus $\mathrm{Li}^{+} / \mathrm{Li}$ in Swagelok-type cells. The pristine material was mixed with $20 \mathrm{wt} \%$ carbon SP by ball-milling for 20 min prior to cycling. A Whatman GF/D borosilicate glass fiber membrane was used as a separator and soaked with LP100 electrolyte. The cells were assembled in an Ar-filled glovebox and were cycled at a $\mathrm{C} / 10$ rate (1 Li removed in $10 \mathrm{~h}$ ) between 2 and $4.8 \mathrm{~V}$ versus $\mathrm{Li}^{+} / \mathrm{Li}$ if not otherwise specified. Samples for $e x$ situ characterization were recovered inside the glovebox, washed thoroughly with anhydrous DMC and dried under vacuum.

\section{Diffraction measurements}

X-ray powder diffraction (XRD) for in situ measurements were done using an airtight electrochemical cell equipped with a Be window in a BRUKER D8 Advance diffractometer with $\mathrm{Cu}$ $\mathrm{K} \alpha$ radiation $\left(\lambda_{\mathrm{K} \alpha 1}=1.54056 \AA, \lambda_{\mathrm{K} \alpha 2}=1.54439 \AA\right)$. Synchrotron X-ray diffraction measurements were performed on the 11-BM beamline of the Advanced Photon Source at Argonne National Laboratory, with a wavelength of $0.41417 \AA$. The powder was mixed with an appropriate amount of amorphous silica to limit absorption, and placed in a sealed quartz capillary $(\varnothing 0.7 \mathrm{~mm}$ ). Neutron powder diffraction (NPD) patterns for the pristine and $4 \mathrm{~V}$ samples were measured on HRPT high-resolution neutron powder diffractometer of the Swiss Spallation Neutron Source SINQ at the Paul Scherrer Institute, with a wavelength of $1.494 \AA$.

\section{Electron microscopy}

Samples for the transmission electron microscopy (TEM) investigation were prepared by grinding samples in a mortar and dipping holey carbon TEM grids into the powder. To prevent exposure of the samples to air they were stored and prepared for TEM in an Ar filled glovebox. A special Gatan vacuum transfer holder was used for the analyses. High-resolution high angle annular dark field scanning transmission electron microscopy (HAADF-STEM) and annular bright field STEM (ABF-STEM) images were acquired on a probe aberration corrected FEI Titan 80-300 electron microscope at $300 \mathrm{kV}$.

\section{X-ray photoemission spectroscopy (XPS)}


XPS measurements were carried out with a Kratos Axis Ultra spectrometer, using focused monochromatic Al $\mathrm{K} \alpha$ radiation $(\mathrm{h} v=1486.6 \mathrm{eV})$. The XPS spectrometer was directly connected through a transfer chamber to an argon dry box, in order to avoid moisture/air exposure of the samples. The analyzed area of the samples was $300 \times 700 \mu \mathrm{m}^{2}$. Peaks were recorded with constant pass energy of $20 \mathrm{eV}$. For the $\mathrm{Ag} 3 \mathrm{~d}_{5 / 2}$ line the full width at half-maximum (FWHM) was $0.58 \mathrm{eV}$ under the recording conditions. The pressure in the analysis chamber was around $5 \times 10^{-9} \mathrm{mbar}$. Short acquisition time spectra were recorded before and after each normal experiment to check that the samples did not suffer from degradation during the measurements. The binding energy scale was calibrated using the $\mathrm{C} 1 \mathrm{~s}$ peak at $285.0 \mathrm{eV}$ from the hydrocarbon contamination invariably present. To avoid any error on the calibration choice and for more precision, binding energy difference between the O1s lattice and metal core peaks was also examined. Core peaks were analyzed using a nonlinear Shirley-type background. ${ }^{24}$ The peak positions and areas were optimized by a weighted least-squares fitting method using 70\% Gaussian, 30\% Lorentzian line shapes. Quantification was performed on the basis of Scofield's relative sensitivity factors. ${ }^{25}$ The curves fit for core peaks were obtained using a minimum number of components in order to fit the experimental curves. For the valence band intensity analyses, a baseline (Shirley-type background) was chosen between 0 and $12 \mathrm{eV}$ approximately according to the experimental shape. The area of the band just below the Fermi level attributed to Ir5d (taking into account the differential photoionization cross sections) was normalized to the area of Ir5p, to evaluate the modification of electronic population of that band during cycling.

\section{DFT calculations}

Spin-polarized density functional theory (DFT) calculations were performed with the plane-wave density functional theory VASP (Vienna Ab initio Simulation Package) code ${ }^{26,27}$ using the generalized gradient approximation of Perdew-Burke-Ernzerhof (PBE) to describe electron exchange and correlation. ${ }^{28}$ The rotationally invariant Dudarev method ${ }^{29}(\mathrm{DFT}+\mathrm{U})$ was used to correct the selfinteraction error of conventional DFT for correlated d-electrons and dispersion corrections of Grimme (D3) ${ }^{30,31}$ were also added to better describe weak van der Waals interactions. All atom coordinates and lattice parameters were fully relaxed using conjugate gradient energy minimization until the forces acting on each atom were less than $5.10^{-3} \mathrm{eV} \AA$. A plane-wave cutoff of $600 \mathrm{eV}$ was used to define the basis set, with well-converged k-point sampling for each compound. The elastic properties of the studied phases were investigated through the computation of the Hessian matrix of fully converged structures and we used a home-made program to plot the 3D representation of the C-matrix components, following Marnier et al. ${ }^{32}$

\section{Acknowledgements}

The authors thank Q. Jacquet for fruitful discussions and Vladimir Pomjakushin for his precious help in neutron diffraction experiments. This work is based on experiments performed at the 
Swiss spallation neutron source SINQ, Paul Scherrer Institute, Villigen, Switzerland. Use of the 11BM mail service of the APS at Argonne National Laboratory was supported by the U.S. department of Energy under contract No. DE-AC02-06CH11357 and is greatly acknowledged. J.-M.T. acknowledges funding from the European Research Council (ERC) (FP/2014)/ERC Grant-Project 670116ARPEMA. E. M. acknowledges financial support from the Fonds de Recherche du Québec - Nature et Technologies.

\section{Authors Contribution}

P.E. P. and J.-M.T. carried out the synthesis; P. E.P., A.J.P. and J.-M.T. did the electrochemical work; E.M. and G.R. conducted the structural analysis; M.S. and M.L.D. did the DFT calculations; D.B., A.M.A. and G.V.T. did the TEM study; D.F. collected and analysed the XPS spectra; G.R. and J.-M.T. wrote the manuscript and all authors discussed the experiments and final manuscript.

\section{Additional Information}

Supplementary information available as pdf file. CIF files of $\beta-\mathrm{Li}_{2} \mathrm{IrO}_{3}$ and $\beta-\mathrm{LiIrO}_{3}$.

\section{Notes}

The authors declare no competing financial interest.

\section{References}

1. Tarascon, J. M. \& Armand, M. Issues and challenges facing rechargeable lithium batteries. Nature 414, 359-367 (2001).

2. Armand, M. \& Tarascon, J. M. Building better batteries. Nature 451, 652-657 (2008).

3. Padhi, A. K., Nanjundaswamy, K. S. \& Goodenough, J. B. Phospho-olivines as positive-electrode materials for rechargeable lithium batteries. Journal of the Electrochemical Society 144, 11881194 (1997).

4. Masquelier, C. \& Croguennec, L. Polyanionic (Phosphates, Silicates, Sulfates) Frameworks as Electrode Materials for Rechargeable Li (or Na) Batteries. Chemical Reviews 113, 6552-6591 (2013). 
5. Rousse, G. \& Tarascon, J. M. Sulfate-Based Polyanionic Compounds for Li-Ion Batteries: Synthesis, Crystal Chemistry, and Electrochemistry Aspects. Chemistry of Materials 26, 394-406 (2014).

6. Lu, Z. H., MacNeil, D. D. \& Dahn, J. R. Layered LiNixCo1-2xMnxO2 cathode materials for lithium-ion batteries. Electrochem. Solid State Lett. 4, A200-A203 (2001).

7. Lu, Z., Beaulieu, L. Y., Donaberger, R. A., Thomas, C. L. \& Dahn, J. R. Synthesis, Structure, and Electrochemical Behavior of Li [ Ni x Li1 / 3-2x/3Mn2/3-x/3 ] O 2. J. Electrochem. Soc. 149, A778-A791 (2002).

8. Johnson, C. S. et al. The significance of the Li2MnO3 component in 'composite' xLi2MnO3 . (1x)LiMn0.5Ni0.5O2 electrodes. Electrochem. Commun. 6, 1085-1091 (2004).

9. Sathiya, M. et al. Reversible anionic redox chemistry in high-capacity layered-oxide electrodes. Nature Materials 12, 827-835 (2013).

10. Sathiya, M. et al. Origin of voltage decay in high-capacity layered oxide electrodes. Nat Mater 14, 230-238 (2015).

11. McCalla, E. et al. Visualization of O-O peroxo-like dimers in high-capacity layered oxides for Liion batteries. Science 350, 1516-1521 (2015).

12. Takayama, T. et al. Hyperhoneycomb Iridate $\beta$ - Li 2 IrO 3 as a Platform for Kitaev Magnetism. Physical Review Letters 114, (2015).

13. Biffin, A. et al. Unconventional magnetic order on the hyperhoneycomb Kitaev lattice in $\$ \$$ lbeta $\$\{\} \backslash$ text $\{-\}\{\backslash \text { mathrm }\{\mathrm{Li}\}\}_{-}\{2\}\{\backslash \text { mathrm }\{\operatorname{IrO}\}\}_{-}\{3\} \$$ : Full solution via magnetic resonant x-ray diffraction. Phys. Rev. B 90, 205116 (2014).

14. Modic, K. A. et al. Realization of a three-dimensional spin-anisotropic harmonic honeycomb iridate. Nature Communications 5, (2014).

15. Kimchi, I., Analytis, J. G. \& Vishwanath, A. Three-dimensional quantum spin liquids in models of harmonic-honeycomb iridates and phase diagram in an infinite- D approximation. Physical Review B 90, (2014).

16. Kimchi, I., Coldea, R. \& Vishwanath, A. Unified theory of spiral magnetism in the harmonichoneycomb iridates $\alpha, \beta$, and $\gamma \mathrm{Li} 2 \mathrm{IrO}$ 3. Physical Review B 91, (2015). 
17. Thackeray, M. M. et al. Li2MnO3-stabilized LiMO2 ( $\mathrm{M}=\mathrm{Mn}, \mathrm{Ni}, \mathrm{Co})$ electrodes for lithium-ion batteries. Journal of Materials Chemistry 17, 3112 (2007).

18. Shannon, R. D. Revised Effective Ionic-Radii and Systematic Studies of Interatomic Distances in Halides and Chalcogenides. Acta Crystallographica Section A 32, 751-767 (1976).

19. Yabuuchi, N. et al. High-capacity electrode materials for rechargeable lithium batteries: Li3NbO4-based system with cation-disordered rocksalt structure. Proc. Natl Acad. Sci. USA 112, 7650-7655 (2015).

20. Freire, M. et al. A new active Li-Mn-O compound for high energy density Li-ion batteries. Nat. Mater. 15, 173-177 (2015).

21. Rouxel, J. Design and chemical reactivity of low dimensional solids - some soft chemistry routes to new solids. Acs Symposium Series 499, 88-113 (1992).

22. Rouxel, J. Anion-cation redox competition and the formation of new compounds in highly covalent systems. Chem.-Eur. J. 2, 1053-1059 (1996).

23. Rouxel, J. The Importance of Anions in redox-type Chimie Douce. Mol. Cryst. Liq. Cryst. Sci. Technol. Sect. A-Mol. Cryst. Liq. Cryst. 310, 1-4 (1998).

24. Shirley, D. A. High-Resolution X-Ray Photoemission Spectrum of the Valence Bands of Gold. Phys. Rev. B 5, 4709-4714 (1972).

25. Scofield, J. H. Hartree-Slater subshell photoionization cross-sections at 1254 and $1487 \mathrm{eV}$. Journal of Electron Spectroscopy and Related Phenomena 8, 129-137 (1976).

26. Kresse, G. \& Hafner, J. Abinitio Molecular-Dynamics for Liquid-Metals. Physical Review B 47, $558-561$ (1993).

27. Kresse, G. \& Furthmuller, J. Efficiency of ab-initio total energy calculations for metals and semiconductors using a plane-wave basis set. Computational Materials Science 6, 15-50 (1996).

28. Perdew, J. P., Burke, K. \& Ernzerhof, M. Generalized gradient approximation made simple. Physical Review Letters 77, 3865-3868 (1996).

29. Dudarev, S. L., Botton, G. A., Savrasov, S. Y., Humphreys, C. J. \& Sutton, A. P. Electron-energyloss spectra and the structural stability of nickel oxide: An LSDA+U study. Phys. Rev. B 57, 1505-1509 (1998). 
30. Grimme, S., Antony, J., Ehrlich, S. \& Krieg, H. A consistent and accurate ab initio parametrization of density functional dispersion correction (DFT-D) for the 94 elements H-Pu. The Journal of Chemical Physics 132, 154104 (2010).

31. Grimme, S., Ehrlich, S. \& Goerigk, L. Effect of the damping function in dispersion corrected density functional theory. Journal of Computational Chemistry 32, 1456-1465 (2011).

32. Marmier, A. et al. ElAM: A computer program for the analysis and representation of anisotropic elastic properties. Computer Physics Communications 181, 2102-2115 (2010). 
Table 1: Crystallographic data and atomic positions of the $4 \mathrm{~V}$-charged $\beta$ - $\mathrm{LiIrO}_{3}$ determined from Rietveld refinement of neutron powder diffraction pattern. A bond valence sum analysis (BVS) (using $d_{0}$ from $\operatorname{Ir}^{4+}$ ) is included.

\begin{tabular}{|c|c|c|c|c|c|c|c|}
\hline \multicolumn{8}{|c|}{$\beta-\mathrm{Li}_{1} \mathrm{IrO}_{3}$} \\
\hline \multicolumn{2}{|c|}{ Space group $F d d d$} & & & \multicolumn{2}{|c|}{$R_{\text {Bragg }}=2.64 \%$} & \multicolumn{2}{|c|}{$\chi^{2}=1.44$} \\
\hline \multicolumn{2}{|c|}{$a=5.62149(6) \AA ̊$} & \multicolumn{2}{|c|}{$b=8.88673(10) \AA$} & \multicolumn{2}{|c|}{$c=17.8518(2) \AA$} & \multicolumn{2}{|c|}{$V=891.815(17) \AA^{3}$} \\
\hline Atom & $\begin{array}{l}\text { Wyckoff } \\
\text { position }\end{array}$ & $x / a$ & $y / b$ & $z / c$ & Occupancy & $B\left(\AA^{2}\right)$ & BVS \\
\hline Ir & $16 \mathrm{~g}$ & $1 / 8$ & $1 / 8$ & $0.70899(11)$ & 1 & $1.54(4)$ & $4.555(13)$ \\
\hline Li3 & $16 f$ & $1 / 8$ & $0.9732(8)$ & $1 / 8$ & 1 & $1.84(13)$ & $0.974(6)$ \\
\hline $\mathrm{O} 1$ & $16 e$ & $0.8566(6)$ & $1 / 8$ & $1 / 8$ & 1 & $1.09(5)$ & $1.906(9)$ \\
\hline $\mathrm{O} 2$ & $32 h$ & $0.6288(7)$ & $0.34651(17)$ & $0.03538(10)$ & 1 & $1.42(4)$ & $1.812(8)$ \\
\hline
\end{tabular}



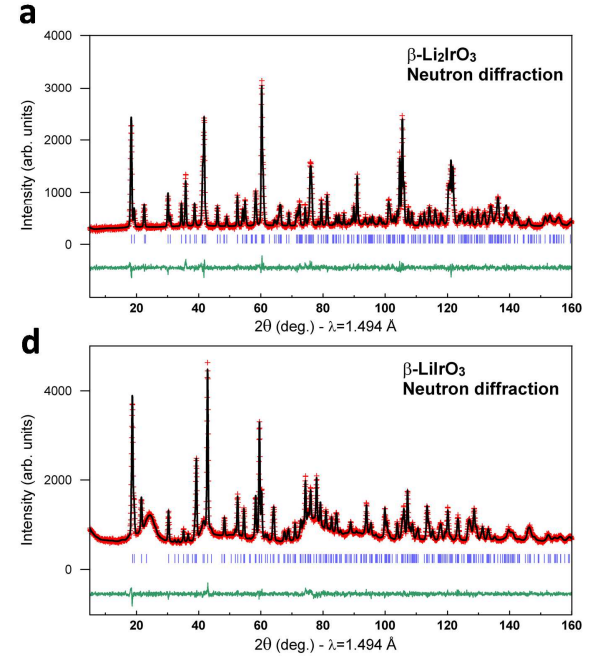
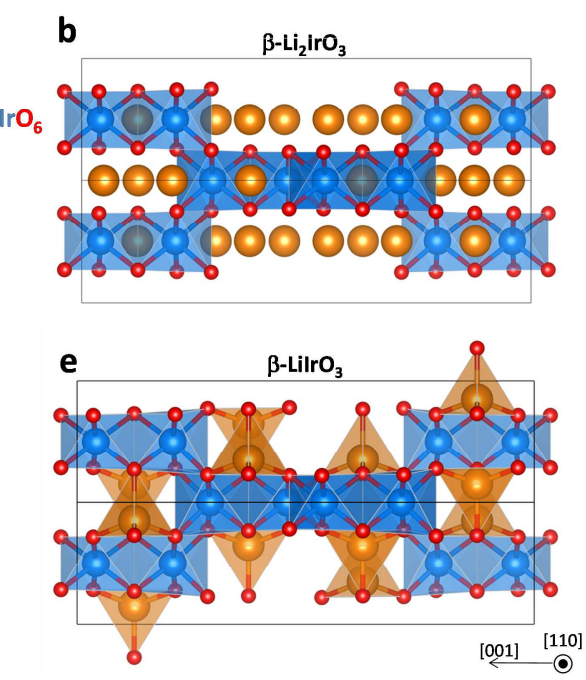

c

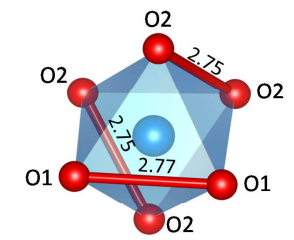

O-O distortion $\Delta\left(\times 10^{4}\right)=5.25$ $\langle\mid r-0\rangle=2.028 \AA$

f

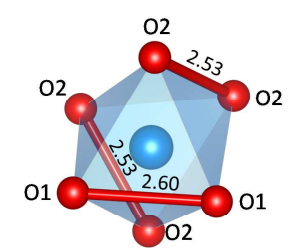

O-O distortion $\Delta\left(\times 10^{4}\right)=25.2$ $\langle\mid r-0\rangle=1.972 \AA$

Figure 1: Structure of $\beta-\mathbf{L i}_{\mathbf{x}} \mathbf{I r O} \mathbf{O}_{3}$. Rietveld refinement of the neutron patterns and resulting structures for $\beta-\mathrm{Li}_{2} \mathrm{IrO}_{3}$ structure $(\mathrm{a}, \mathrm{b}, \mathrm{c})$ and $4 \mathrm{~V}$-charged $\beta$-LiIrO $(\mathrm{d}, \mathrm{e}, \mathrm{f})$. In red are the experimental points, in black are the calculated patterns and in green are the differences between the experimental and calculated patterns. The vertical blue lines beneath the patterns indicate the positions of the Bragg reflections. In (d), the broad peaks at $2 \theta \sim 25^{\circ}, 42^{\circ}, 80^{\circ}$ are from carbon. For the structural models, $\mathrm{Li}$ is orange, $\mathrm{Ir}$ is blue, $\mathrm{O}$ is red. Note that $\mathrm{Li}$ is in octahedral position in $\beta$ - $\mathrm{Li}_{2} \mathrm{IrO}_{3}$ (b) and in tetrahedral positions in 4 V-charged $\beta$ - $\mathrm{LiIrO}_{3}$ (e).Also shown is the evolution of the $\mathrm{IrO}_{6}$ octahedron from the pristine $\beta-\mathrm{Li}_{2} \mathrm{IrO}_{3}$ state (c) to the $4 \mathrm{~V} \mathrm{LiIrO}{ }_{3}$ compound (f). The average Ir-O distance is given (indicative of the $\mathrm{Ir}^{4+}$ oxidation), and we estimate the O-O distortion with the formula: $\Delta=\frac{1}{12} \sum_{i=1}^{12}\left[\frac{\left.d_{i}-<d\right\rangle}{<d\rangle}\right]^{2}$ with $\mathrm{d}_{i}$ the individual O-O distances. The shortest O-O distances in the octahedral are highlighted in red with their distance $(\AA)$ reported. 

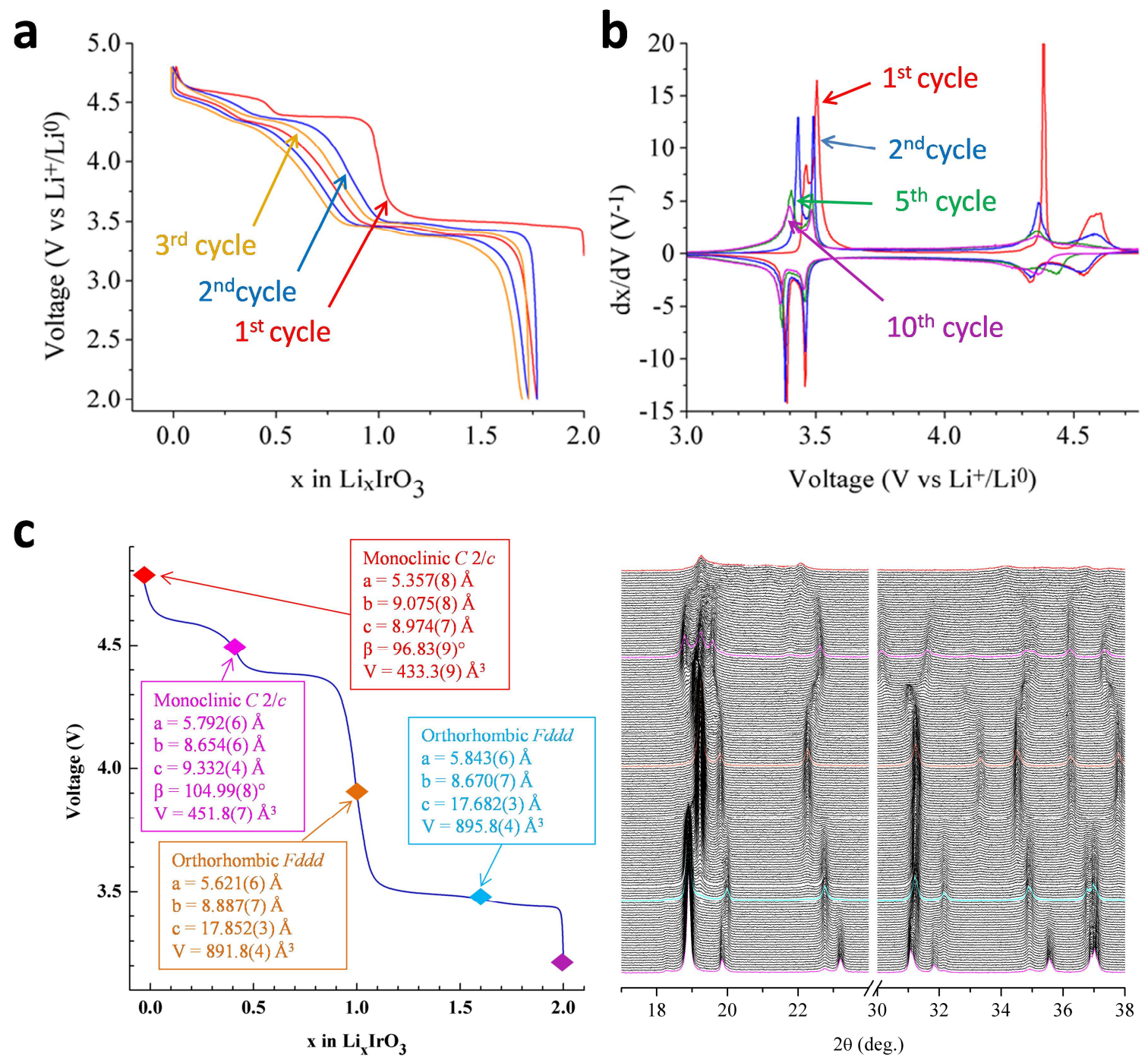

Figure 2: Electrochemical data for $\boldsymbol{\beta}-\mathbf{L i}_{\mathbf{x}} \mathbf{I r O}_{3}$. (a) The voltage profiles for the first 3 cycles of $\beta-\mathrm{Li}_{2} \mathrm{IrO}_{3}$ versus $\mathrm{Li}^{+} / \mathrm{Li}^{0}$ at $\mathrm{C} / 10$ rate. (b) The corresponding derivative plots $\mathrm{dx} / \mathrm{dV}$ for the cycles 1 to 10. (c) The in situ XRD patterns of $\beta-\mathrm{Li}_{2} \mathrm{IrO}_{3}$ shown on the right and the corresponding charge profile on the left. The markers on the charge profile indicate the points where intermediate phases were isolated and the XRD data were refined. Space group, lattice parameters and unit cell volumes of key compositions are indicated. 
(a)

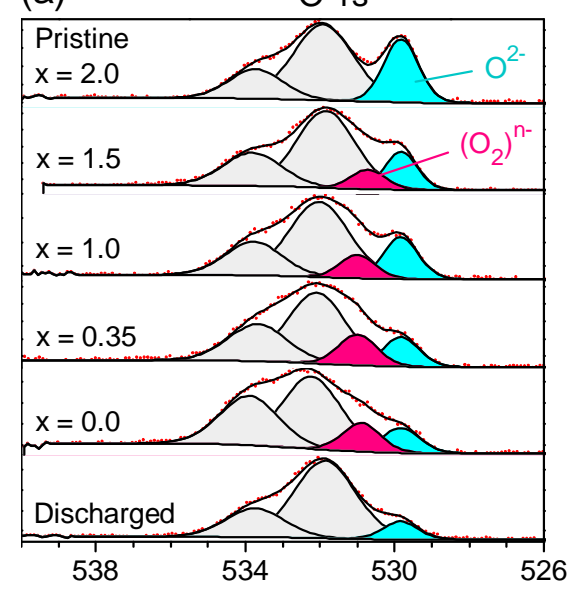

(b)

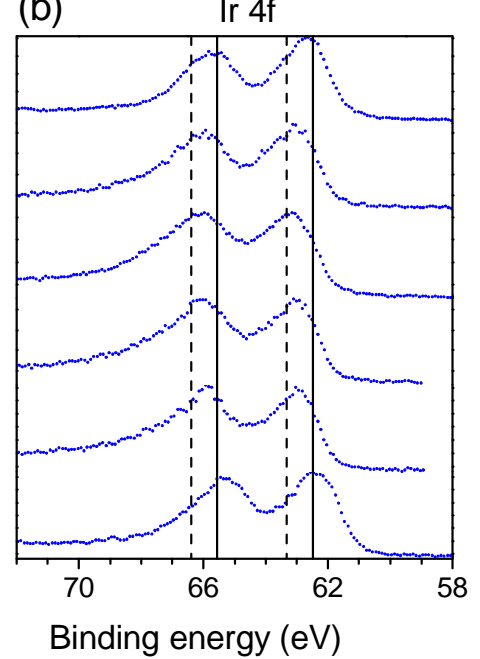

(c) Valence band spectra

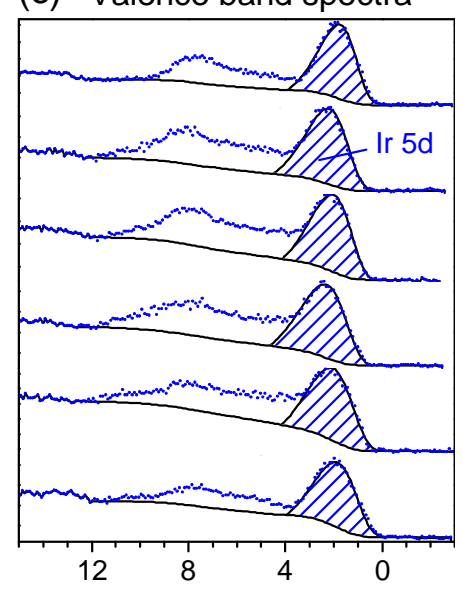

(d)

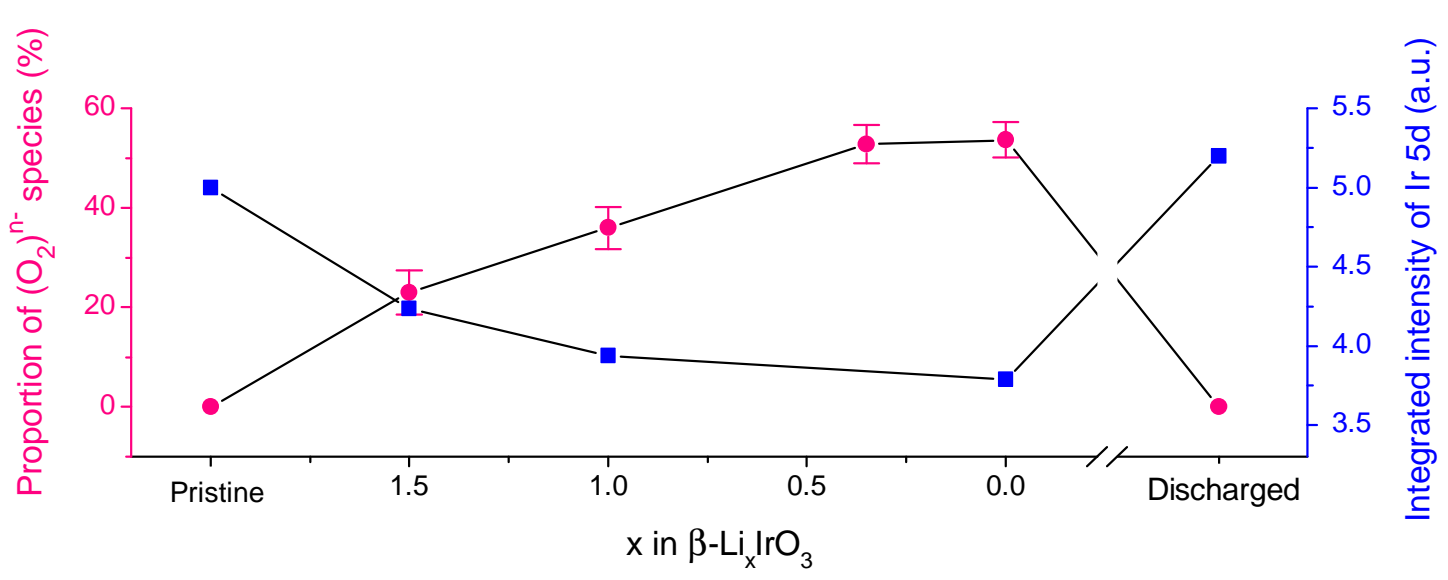

Figure 3: XPS analysis. (a) and (b) O 1s and Ir 4f XPS core spectra collected ex situ for $\beta-\mathrm{Li}_{\mathrm{x}} \mathrm{IrO}_{3}$ at various states of charge and discharge. (c) The valence band spectra at various points in the electrochemical cycle with the hatched area representing the spectral participation of Ir 5d in this band. (d) The $x$ dependence of the fraction of lattice oxygen attributed to peroxo-like species and the integrated intensity of the Ir $5 \mathrm{~d}$ band, normalized to the area of Ir $5 p$ peak. 

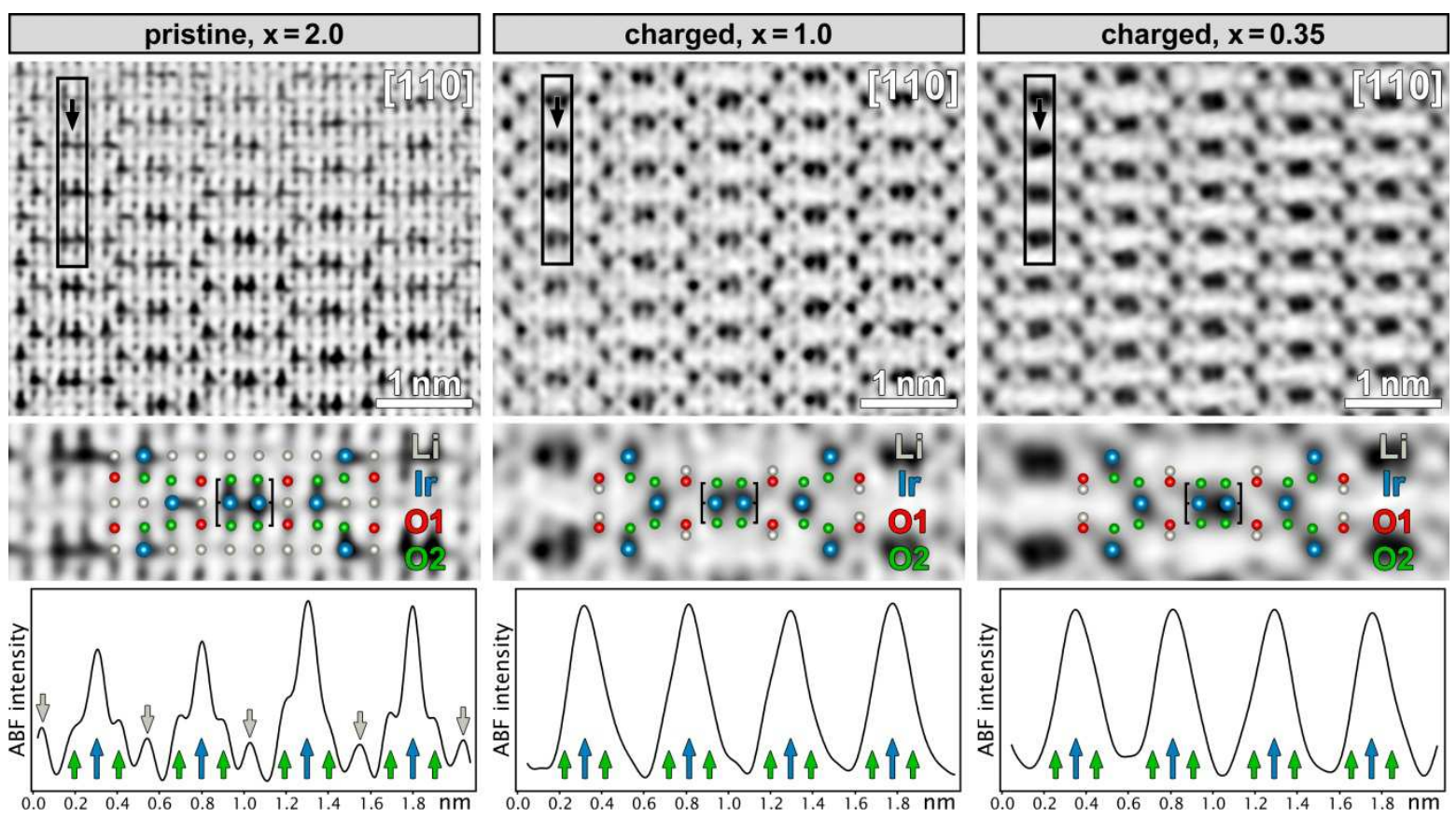

Figure 4: Local structure of $\beta-\mathbf{L i}_{\mathbf{x}} \mathbf{I r O}_{3}$. [110] ABF-STEM images of the pristine $\beta-\mathrm{Li}_{2} \mathrm{IrO}_{3}$ and two charged $\mathrm{Li}_{\mathrm{x}} \mathrm{IrO}_{3}$ materials with $\mathrm{x}=1.0$ and $\mathrm{x}=0.35$. The correspondence between the images and the projected structure of the materials is demonstrated on the magnified ABFSTEM in the middle ( $\times 2$ ). Intensity profiles highlight the structure changes in the material upon charging, i.e. the vanishing of the Li signal and formation of shortened projected Ir-O2 distances. The profiles are measured in the rectangular regions indicated in the images and integrated over the width. The arrows indicate the approximate position of the atomic columns in the profiles. 

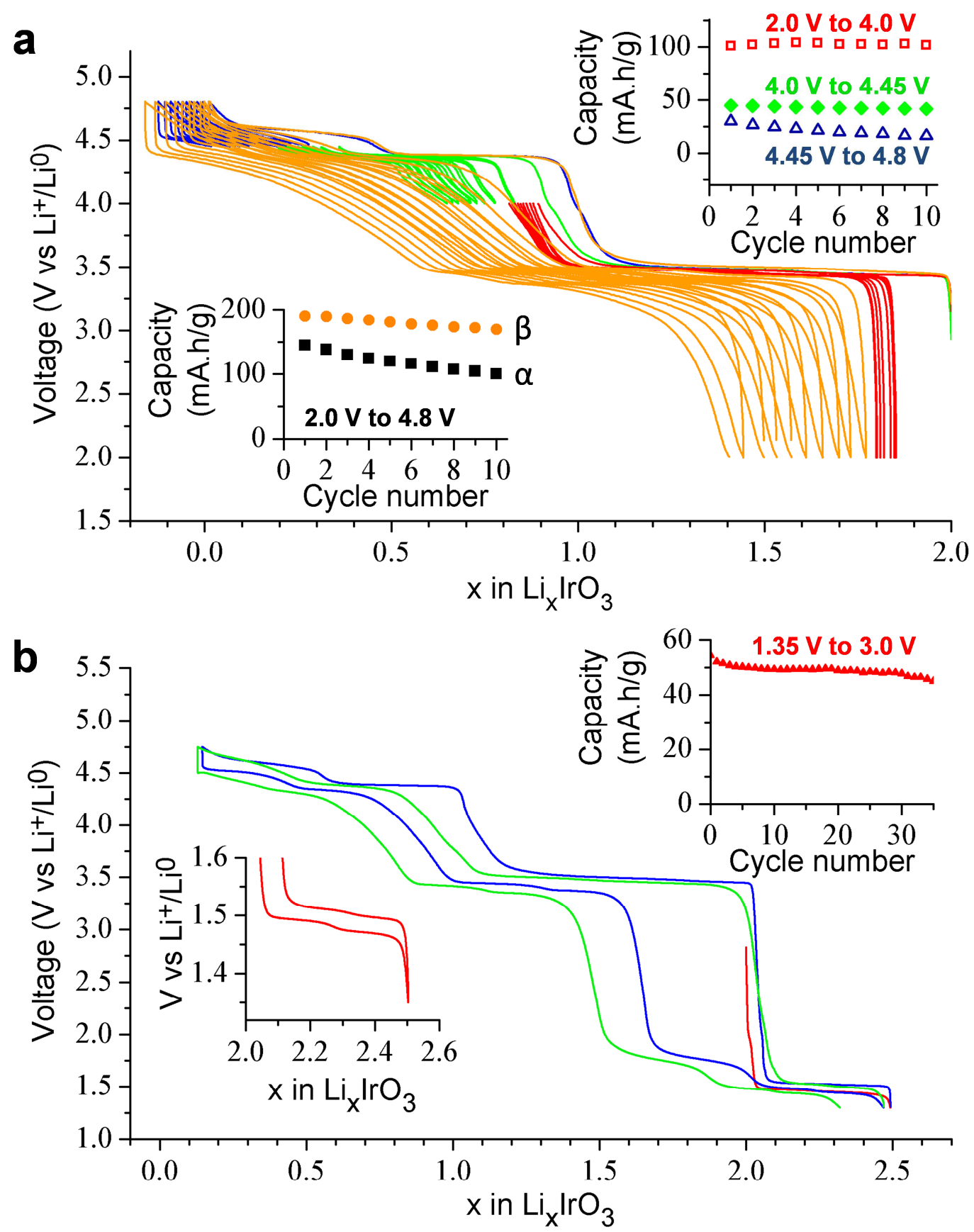

Figure 5: Cycling behavior of $\beta$ - $\mathbf{L i}_{\mathbf{x}} \mathbf{I r O}_{3}$. (a) Voltage-composition curves for $\beta-\mathrm{Li}_{2} \mathrm{IrO}_{3} / \mathrm{Li}$ cells cycled over different voltage ranges together with their corresponding capacity retention in the upper inset. The lower inset shows the capacity retention over the full $2 \mathrm{~V}-4.8 \mathrm{~V}$ range compared to the one of the layered $\alpha$ polymorph cycled in the same voltage range. (b) The voltage composition profile for a similar cell started on discharge (reduction down to $1.35 \mathrm{~V}$, red part of the curve together with a zoom of the low voltage region as an inset) and then cycled from 1.35 to $4.8 \mathrm{~V}$ (only 2 cycles are shown). The capacity retention of the low voltage plateau is shown in the upper inset. 
a
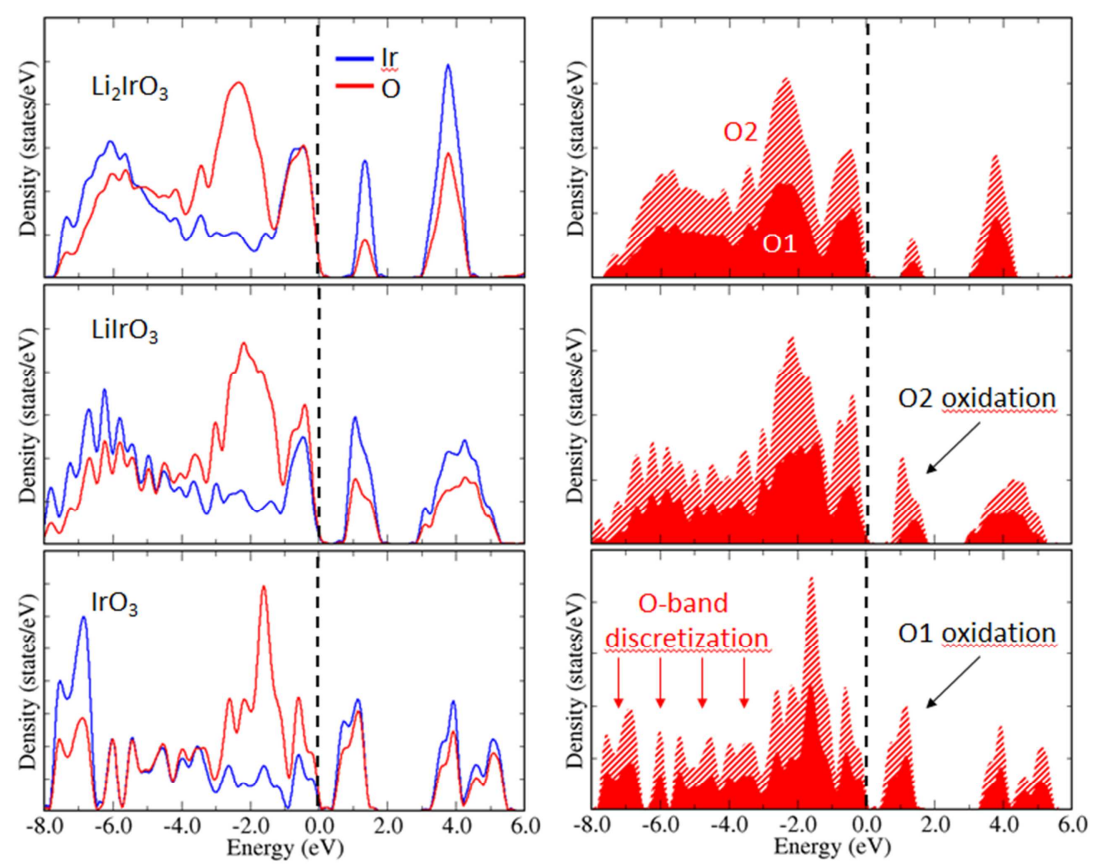

b

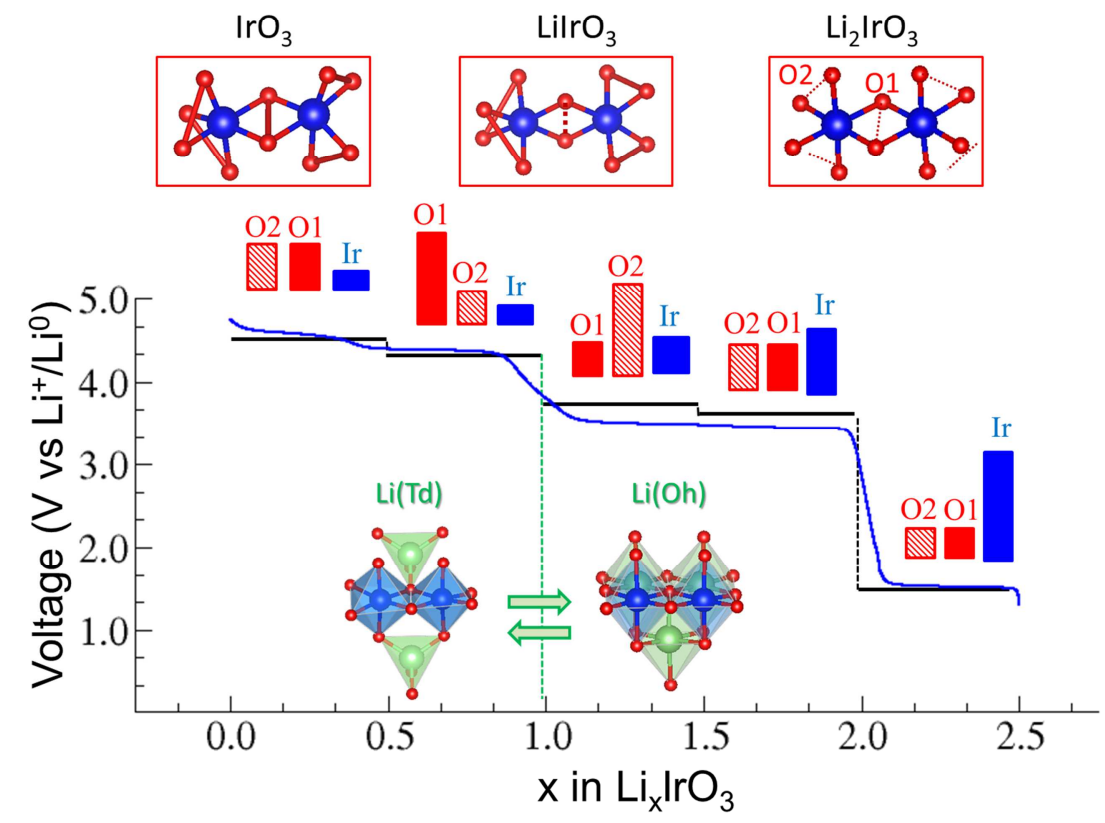

Figure 6: Electronic structures and computed voltages. (a) Density of states (DOS) projected over the Ir and $\mathrm{O}$ atoms (left) and over $\mathrm{O} 1$ and $\mathrm{O} 2$ atoms (right) at Li compositions $\mathrm{Li}_{2} \mathrm{IrO}_{3}, \mathrm{LiIrO}_{3}$ and $\mathrm{IrO}_{3}$. The Fermi level is indicated by the vertical dashed lines. Upon delithiation, the large oxygen band at $\mathrm{x}=2$ progressively split into narrower bands corresponding to the discretization of $\mathrm{O}(2 \mathrm{p})$ levels into $\sigma, \sigma^{*}, \pi, \pi^{*}$ levels of the O-O peroxolike species. The evolution of the contribution of $\mathrm{O} 1$ and $\mathrm{O} 2$ in the band lying just above the Fermi level indicates the degree of oxidation of the different oxygens and it shows that $\mathrm{O} 2$ is mainly involved in the first process $\left(\mathrm{Li}_{2} \mathrm{IrO}_{3} / \mathrm{LiIrO}_{3}\right)$ while $\mathrm{O} 1$ is mainly involved in the second process, in full agreement with the evolution of the O1-O1 and O2-O2 shortest distances listed in Supplementary Information, Table S4. (b) The histogram of the relative contributions of $\mathrm{O} 1, \mathrm{O} 2$ and $\mathrm{Ir}$ in each electrochemical process shown on a composition- 
voltage curve where the computed average voltages (black horizontal lines) are compared to the experimental data (grey). The jump in potential from the low- to the high-voltage process is highlighted in green. The local structures of the $\mathrm{IrO}_{6}$ dimers are given to illustrate the main distortions occurring during the first process from $\mathrm{Li}_{2} \mathrm{IrO}_{3}$ to $\mathrm{LiIrO}_{3}(\mathrm{O} 2-\mathrm{O} 2$ shortening $)$ and the second process from $\mathrm{LiIrO}_{3}$ to $\mathrm{IrO}_{3}$ (O1-O1 shortening). 